\title{
Applying Substance-Field Model for Packaging Quality Improvement
}

\author{
Nikalus Shu Luing Swee ${ }^{1}$ \\ Department of Computer Science and Mathematics, Tunku Abdul Rahman University College, Malaysia ${ }^{1}$ \\ Email: sweesl@acd.tarc.edu.my ${ }^{1}$ \\ Guat Guan Toh ${ }^{2}$, Mum Wai Yip ${ }^{3}$, Chee Sheng Keong ${ }^{5}$, See Chew Tai ${ }^{5}$ \\ Deputy Branch Campus Head, Tunku Abdul Rahman University College, Malaysia ${ }^{2}$ \\ Department of Mechanical Engineering, Tunku Abdul Rahman University College, Malaysia ${ }^{3}$ \\ Department of Chemistry \& Biology, Tunku Abdul Rahman University College, Malaysia ${ }^{4}$ \\ Department of Electronic Engineering, Tunku Abdul Rahman University College, Malaysia ${ }^{5}$ \\ Email: tohgg@acd.tarc.edu.my ${ }^{2}$ \\ Email: yipmw@acd.tarc.edu.my ${ }^{3}$ \\ Email: keongcs@acd.tarc.edu.my ${ }^{4}$ \\ Email: taisc@acd.tarc.edu.my ${ }^{5}$
}

\section{Corresponding Author: sweesl@acd.tarc.edu.my}

\begin{abstract}
This paper aims to provide a thorough analysis on the application of TRIZ in improving the quality of medical product assembly and packaging. TRIZ tools such as engineering system analysis, function analysis, cause and effect chain analysis, substance-field model and 76 Standard Inventive Solutions are applied in order to discover some feasible and elegant solutions to alleviate the problem without making the machine more complex. Findings revealed that the problem of defective packaging is caused by the dust/air particles. Failure for a visioning system to detect the rejected printing on the package and inconsistent sealing integrity is caused by uneven surface of the package. The root causes are solved by applying substance-field model, System of Standard Inventive algorithm and 76 Standard Inventive Solutions. Therefore, it can be concluded that substance-field model of TRIZ is a powerful tool in inventive problem solving.
\end{abstract}

Keywords: Substance-field model, 76 Standard Inventive Solutions, visioning, packaging, TRIZ.

\section{Introduction}

Packaging processes include inspecting, labeling, and packing the final product before the product is released. Equipments, materials and human resources influence the reliability and capacity of the packaging operation. Therefore, identifying bottleneck resources and employing an effective scheduling structure for the packaging process were critical ${ }^{(1)}$. The necessities for packaging medical products have becoming a new technology driver for medical tools and products industry. Based on the forecasts, lots of ideas are being developed in order to meet the demand of an industry requiring more complex devices which show higher reliability, speedy production and lower $\operatorname{cost}^{(2,3)}$. There are great challenges in handling packaging process. The packaging technologies need to know about the issues of downstream handling, especially loading and unloading of goods, and transportation by all channels ${ }^{(3)}$. The packaging applications commonly include vision-guidance of high-speed robots in product packing with simultaneous rejection of substandard items, robotic fish-filleting, color-sorting and grading of capsicum peppers, counting glass anesthesia vials in a tray, and detecting the tracks on the circuit board in a medical device $^{(4)}$. Many of the applications concerned traceability: for example, checking the presence and readability of date codes and bar codes on product packaging, and checking the labeling and etc. ${ }^{(4)}$. Packaging methods change as the medical industry and its requirements change. In the US and in Europe, single-use and disposable medical devices are replacing multiple-use applications at the accelerated 
rates owing to the litigation pressures ${ }^{(5)}$. Furthermore, all packaging companies are urged to use biodegradable materials such as PLA or Mater-Bi resin which are derived from plant sources. Around $95 \%$ of bio-plastics are biodegradable ${ }^{(6,7)}$.

TRIZ is a Russian acronym for "Teoriya Resheniya Izobreatatelskikh Zadatch", equivalent to "Theory of Inventive Problem Solving" in English. TRIZ methodology was founded in 1940's by Genrich Altshuller and his team. He was an inventor, a writer and a patent engineer who studied intellectual property contained in approximately 200,000 patents ${ }^{(8)}$. He discovered and organized his study of 40,000 patents according to innovative patterns of design as well as the inventive principles in these innovative solutions. Findings revealed that problems and solutions, patterns of technical evolution were repeated across industries and sciences, and innovations used scientific effects outside the field where they were developed. Therefore, Genrich Altshuller developed 40 inventive principles ${ }^{(8-15)}$. TRIZ has several essential tools such as function analysis, cause and effect chain analysis, trimming, engineering contradiction, substance-field model, Trends of Engineering System Evolutions, ARIZ, and etc. TRIZ uses 40 inventive principles and 39 parameters to help inventors to derive many solutions ${ }^{(8-15)}$.

\section{Problem statement}

The packages of medical product contain air particles/dust/hairs. Particles in the air can be easily attracted to the plastic material which can be highly electrostatic in nature i.e. can be charged up through friction or triboelectric charging. The package seal width is not consistent. Therefore the package may be torn during transportation, loading and unloading. Fail to detect defective printing quality on the package surface (dirtiness) and the printed product information. The following is the detail on how TRIZ is applied in this case study.

\section{TRIZ models and tools}

TRIZ flow process is shown in Fig. 1. First and foremost, research and brainstorming help identify the original problem to resolve, and this is followed by function analysis, cause and effect chain analysis and substance-field model (Su-Field model). Finally, system of standard inventive algorithm proposes classes of inventive solutions in the 76 Standard Inventive Solutions, in which it leads to specific solution(s) ${ }^{(8,9)}$.

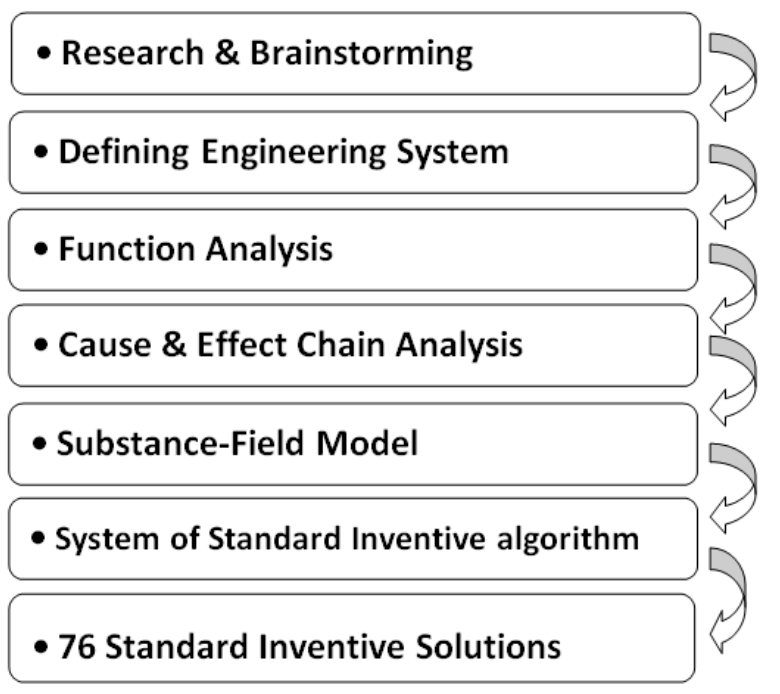

Fig. 1. TRIZ Flow Process

\subsection{Engineering System Definition}

An Engineering System has several components that are interacted among each other. These components are commonly accepted as system and subsystem components that are listed in Table 1. Along with system components, there are also interactions between engineering system and external entities called supersystems. Supersystems are not designed as part of the Engineering System; however, they can influence or impact the Engineering System ${ }^{(8,9)}$.

Table 1. Engineering System

\begin{tabular}{|c|c|}
\hline $\begin{array}{c}\text { Sub/System } \\
\text { Components }\end{array}$ & $\begin{array}{r}\text { plastic film, visioning system, } \\
\text { thermal seal, product containers, } \\
\text { conveyor belt }\end{array}$ \\
\hline Supersystems & $\begin{array}{r}\text { consumers, air particles/dust, } \\
\text { workers, freight }\end{array}$ \\
\hline
\end{tabular}

\subsection{Function Analysis}

Function analysis shows the interactions between two or more systems/subsystems (Engineering System components) which are listed in Fig. 2. These interactions are called functions. Functions are simply actions between two components, i.e., a subject and an object in which the subject acts upon and modifies a parameter(s) of the object (8). Two main types of functions are useful function and harmful function. As for useful function, it comprises of 


\subsection{Substance-Field Modeling (Su-Field model)}

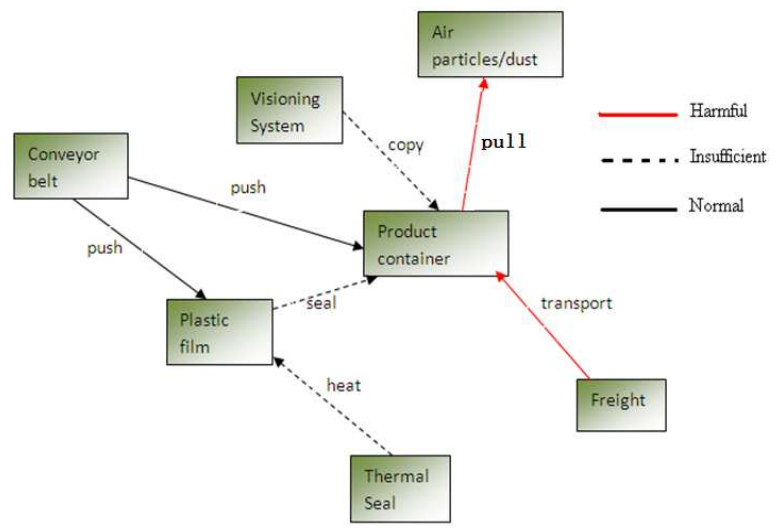

Fig. 2. Function Model

\subsection{Cause and Effect Chain Analysis}

The following stage is Cause and effect chain analysis(CECA). CECA is a vital tool in the TRIZ methodology. It helps identify the right root cause(s) pertaining to the problem in Fig. 3. If we get the wrong root cause, the solution derived may not be effective. Elementarily, CECA is very similar to "5 Whys". We prompt for causes continuously for the problem from high level causes to low level causes by asking "the question "why?" (8).

From the CECA, the root causes identified are the existence of dust/air particles in the production floor brought in by workers, undetected blurred printing and dirtiness on packages due to uneven package surface, and inconsistent package seal width due to air particles/dust.

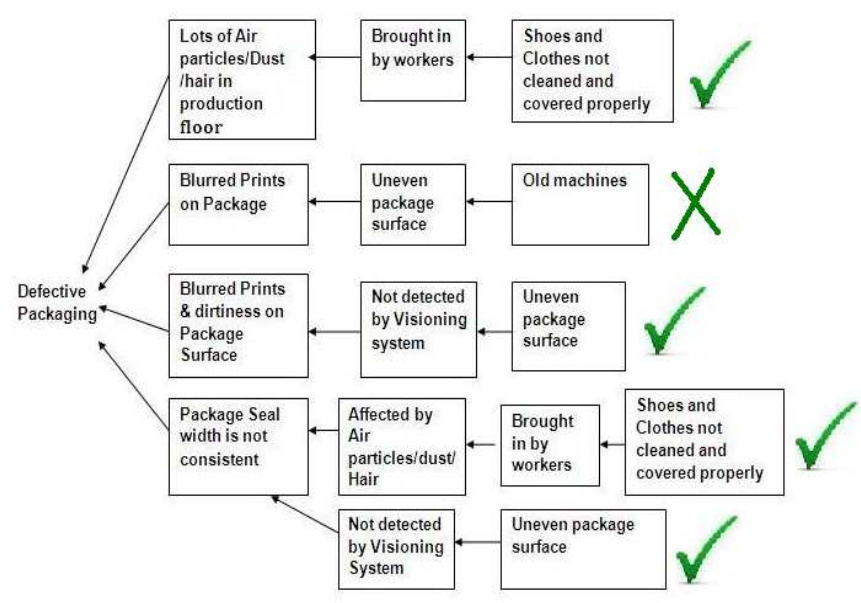

Fig. 3. Cause and Effect Chain Analysis Diagram
Su-Field model depicts a method of modeling a problem as two substances ( 2 objects) that interact through a field. The problem is defined as a specific type of interaction that needs to be improved as shown in Fig. 4. There are 4 types of Su-Field models which are used to model a problem, i.e. Incomplete Su-Field model, Ineffective Su-Field model, Harmful Su-Field model, and Measurement and Detection Su-Field model ${ }^{(8)}$.
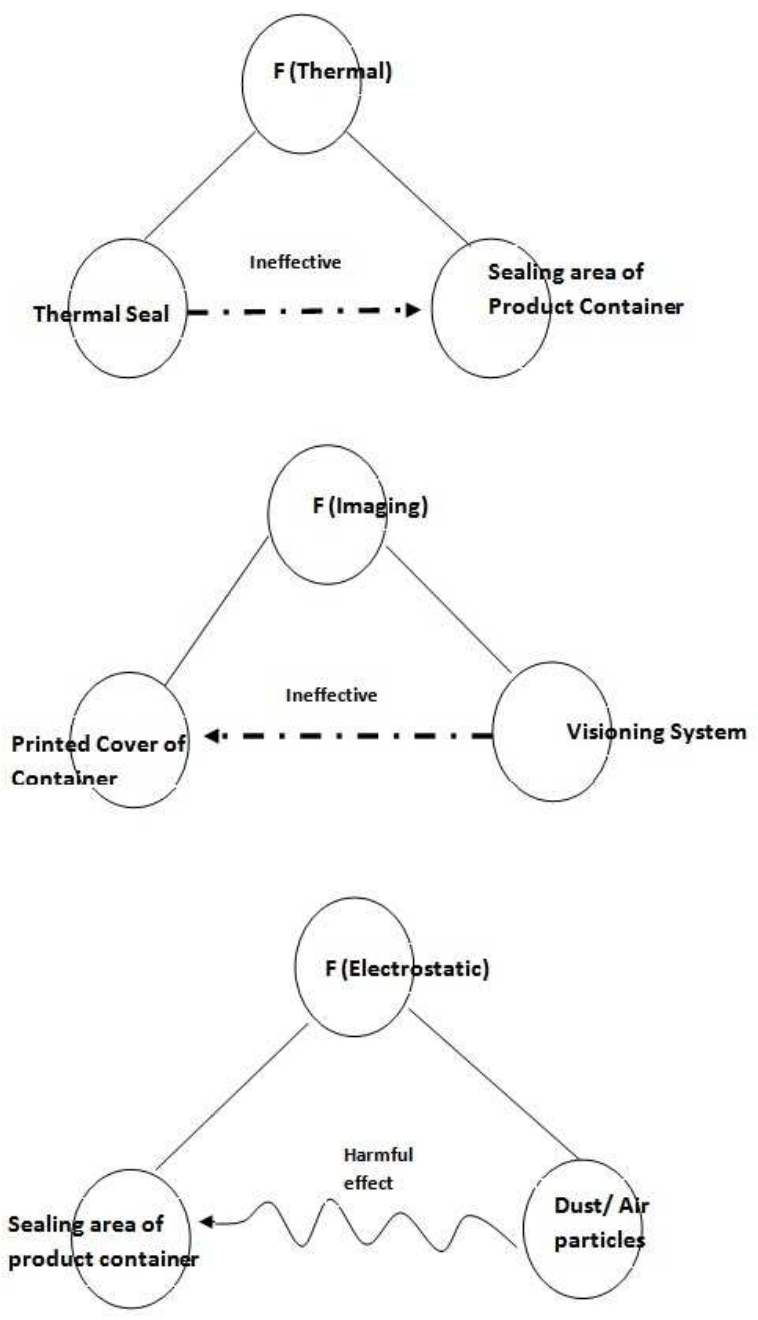

Fig. 4. Substance-field Model 

(Appendix)

With reference to the Su-Field model in Fig. 4, we discovered that the dust and the product container are harmful Su-Field models. The thermal seal and product container is an ineffective/insufficient Su-Field model. Therefore, we scrutinize the System of Standard Inventive Solution algorithm and subsequently we have grasped several recommendations from the 76 Standard Inventive Solutions ${ }^{(16)}$. The System of Standard Inventive Solution algorithm proposes Class 1.2 Standard Inventive Solutions for the harmful Su-Field model and Class 2, 3 for the ineffective Su-Field model. After thorough study with field specialists, the detail of selected inventive solutions from Class 1.2 and 2 in the "76 Standard Inventive Solutions" are as the following:

\section{Class 1.2 Eliminating or neutralizing harmful effects \\ 11 1.2.3. The harmful action is caused by a field. Introduce an element S3 to absorb the harmful effects. \\ Class 2 Increase Su-Field Effectiveness}

27 2.4.3. Use a magnetic liquid where a magnetic liquid is colloidal ferromagnetic particles suspended in kerosene, silicone or water. Use gas or liquid parts of an object instead of solid parts. e.g. hydro-reactive, vacuum pick and place equipment

The "76 Standard Inventive Solutions" of TRIZ were compiled by G.S. Altshuller and his associates between 1975 and1985. They are grouped into 5 large categories in Table 2 as follows:

Table 2. 76 Standard Inventive Solutions

\begin{tabular}{|c|c|}
\hline 1. Build or destroy Su-Field & 13 standard solutions \\
\hline 2. Increase Su-Field effectiveness & 23 standard solutions \\
\hline 3. System transitions & 6 standard solutions \\
\hline 4. Detection and measurement & 17 standard solutions \\
\hline 5. Strategies to apply Class & 17 standard solutions \\
\hline Total: & 76 standard solutions \\
\hline
\end{tabular}

\section{TRIZ solutions and discussion}

\subsection{Solutions for Harmful Effect Su-Field model}

With reference to 76 Standard Inventive Solutions Class 1.2, in the context of the existence of air particles/dust in the production floor that may cause inconsistent package seal width, we found that Class 1.2.3. "The harmful action is caused by a field. Introduce an element S3 to absorb the harmful effects" is appropriate. We propose intermediaries to block the dirt from being carried into the production floor by imposing shoe covers and smocks on every worker in the production floor. This may help to eradicate the dusty production floor.

\subsection{Solutions for Ineffective Su-Field model}

With reference to 76 Standard Inventive Solutions Class 2 and 3, in the context of undetected blurred printing, dirtiness on packages due to uneven package surface and inconsistent package seal width, we found that Class 2.4.3 "Use magnetic liquid" is deemed appropriate for our problem. Class 2.4.3 suggests to use gas or liquid parts of an object instead of solid parts, e.g. hydro-reactive, vacuum pick and place equipment and etc. . Hence, vacuum suction is introduced. To permit visioning system to check for sealing integrity and correct printing on each packet effectively, vacuum suction is applied underneath each packet/package. This will make the bottom side of each packet to stick to the vacuum underneath. Vacuum holes or vacuum lines can be installed at the perimeter of each packet to suck the packet in order to keep the sealing area as planar and horizontal as possible ${ }^{(17)}$. Therefore, the visioning system is able to detect all packaging problems comprising of dirtiness packet, inconsistent sealing width and blurred printing on packets effectively.

\section{Conclusions}

The ever improving technology in packaging should be able to handle any sizes of products in a speedy, reliable, and cheaper cost ${ }^{(2,3)}$. In this case study, the problem can be contained and lessened by applying TRIZ tools particularly the Su-Field model and 76 Standard Inventive Solutions. Su-Field model helps engineers to generate more feasible ideas or concepts which may lead to elegant 
solutions. It can be concluded that Su-Field model and 76 Standard Inventive Solutions are innovative problem solving methodology.

\section{References}

(1) Schruben, Lee. "Graphical simulation modeling and analysis: Using Sigma ${ }^{\circledR}$ for Windows (The Scientific Press Series)", Cambridge, MA: Course Technology, 1994

(2) Andy Longford, "Chip packaging challenges . . . a roadmap based overview", Microelectronics International, 22/2, pp. 17-20. 2005

(3) Lagner, P., “Advantest Handling challenges of small \& fine pitch devices", Advantest Technical Forum, January 2004

(4) Christine Connolly, "Sensor trends in processing and packaging of foods and pharmaceuticals", 27/2, pp.103-108, 2007

(5) Podojil, Bill, "Opportunities in medical packaging", Film and Foil Converter; 77, 2, 2003

(6) Abdullah Al Mamun, "Natural bio-fibre composites are emerging as a viable alternative to synthetic fibre-reinforced composites especially in the automotive and building industries", Chemistry \& Industry, 27 July 2009

(7) Aniruddh Menon, "A major concern for end users is price/performance ratio - and this is one of the factors that will decide the fate of bioplastics", Chemistry \& Industry, 27 July 2009

(8) T.S. Yeoh, T.J. Yeoh, and C.L. Song, "TRIZSystematic Innovation in Manufacturing”, Selangor: Firstfruits, 2009

(9) A.A. Guin, A.V. Kudryavtsev, V. Yu. Boubentsov, A. Seredinsky, "Theory of Inventive Problem Solving", First Fruits, 2009

(10) D. Mann, "Hands-On Systematic Innovation", Belgium: CREAX Press, 2003

(11)D. Mann, "Hands-On Systematic Innovation for Business and Management", Devon: Lazarus Press, 2007

(12)E. M. Smith, "From Russia with TRIZ", Mechanical Engineering, 125, 3; Academic Research Library, pp. D18. 2003

(13) G.S. Altshuller, "The Innovation Algorithm, TRIZ Systematic Innovation and Technical Creativity", Worcester, MA: Technical Innovation Centre, 2000
(14) G.S. Altshuller, "40 Principles, TRIZ Keys to Technical Innovation”, Worcester, MA: Technical Innovation Centre, 2002

(15) J. Terninko, A. Zusman, and B. Zlotin, "Systematic Innovation: An Introduction to TRIZ”, New York, NY: CRC Press, 2010

(16) J. Terninko, E. Domb, J. Miller, E. MacGran, "The Seventy-Six Standard Solutions: How They Relate to the 40 Principles of Inventive Problem Solving”, The TRIZ Journal, May 1999.

(17) Zalud, Todd, "Using suction cups to design a vacuum system”, Machine Design;70, 22; pp. 114, 1998.

\section{Appendix}
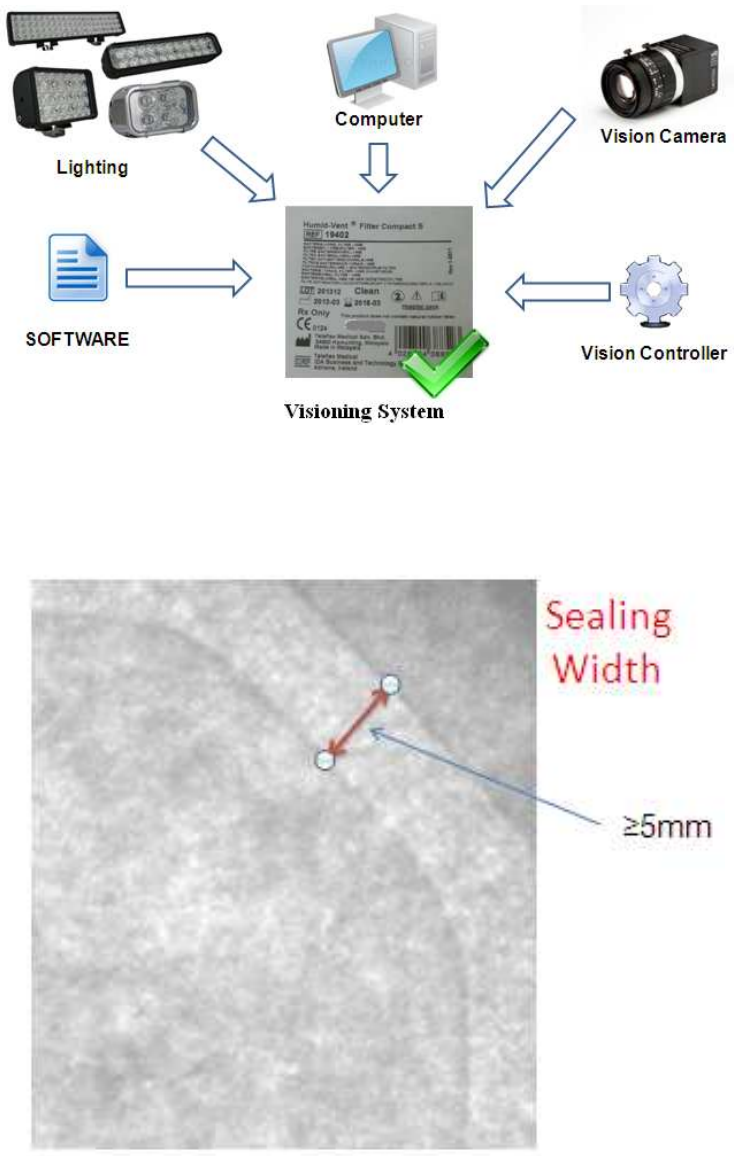
System of Standard Inventive Solutions

algorithm

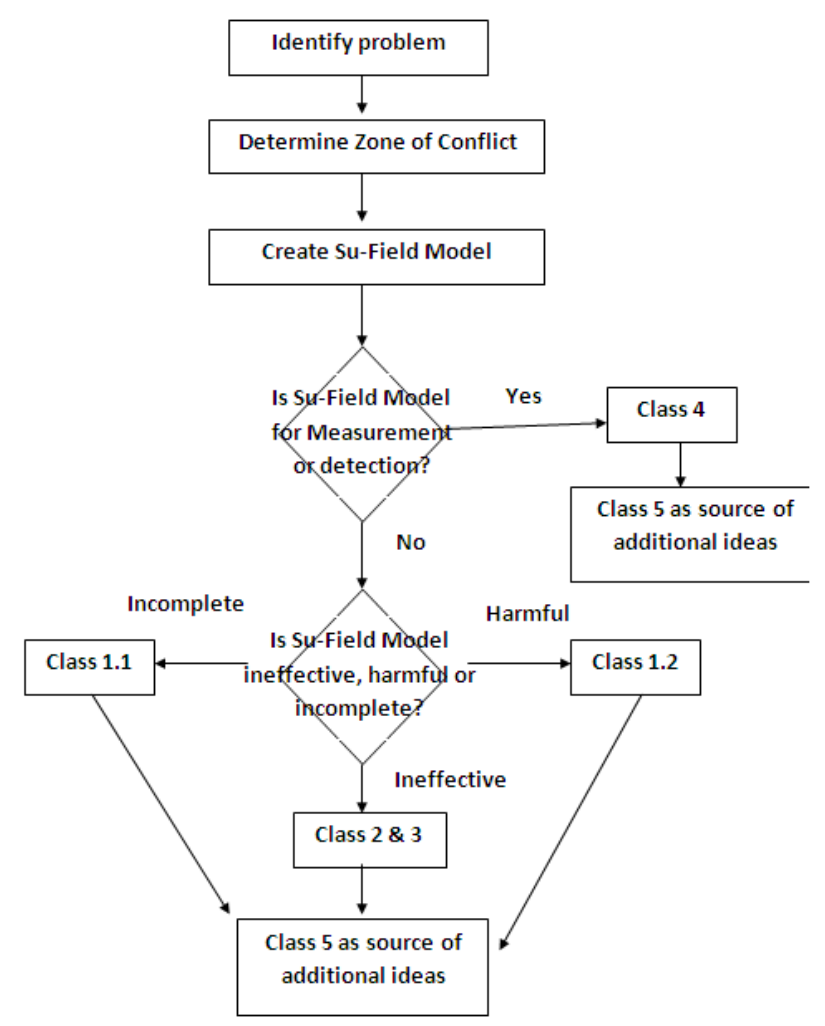

